\title{
КЛИНИКО-АМНЕСТИЧЕСКИЕ И СТРУКТУРНО-ФУНКЦИОНАЛЬНЫЕ ПОКАЗАТЕЛИ У БОЛЬНЫХ САХАРНЫМ ДИАБЕТОМ 2 ТИПА С НАЛИЧИЕМ НЕЙРОДЕГЕНЕРАТИВНЫХ ИЗМЕНЕНИЙ СЕТЧАТКИ
}

\section{CLINICAL, AMNESTIC AND MORPHOFUNCTIONAL PARAMETERS IN PATIENTS WITH TYPE2 DIABETES MELLITUS WITH NEURODEGENERATION OF RETINA}

\section{Ruchkin \\ E. Makarevich \\ E. Markelova \\ G. Fedyashev}

Summary. In this study we have included 40 patients with confirmed diagnosis of diabetes mellitus type 2 (main group) and 30 healthy volunteers (control group). All patients have been examined with optic coherence tomography RTVue-100 («0ptovue», USA) and microperimetry «MAIA» (CenterVue, Italy).

Analyze result of microperimetry we have revealed reliable $(p=0,001)$ decrease of average sensitivity of retina in patients of the main group. Analyze results of OCT we have revealed reliable $(p=0,01)$ difference in focal loss volume, in main group. These changes haven't any dependence from clinical signs of diabetic retinopathy and this conclusion confirm that neurodegeneration begins earlier than vascular damage. In patients with diabetic neuropathy neurodegeneration of retina reveals more often.

Keywords: diabetes mellitus, diabetic retinopathy, neurodegeneration, microperimetry, optic coherence tomography.

\section{Введение}

о обновленным данным международной федерации диабета в мире насчитывается 463 млн. больных сахарным диабетом (СД), предполагается, что к 2045 году эта цифра достигнет 700 млн. [9].
Ручкин Михаил Петрович

Аспирант, ФГБОУВО «Тихоокеанский Государственный Медицинский Университет» Минздрава России (г. Владивосток) michaelr-n@mail.ru

Макаревич Екатерина Сергеевна

Ординатор, ФГБОУВО «Тихоокеанский Государственный Медицинский Университет» Минздрава России (2. Владивосток) katyuha-m@mail.ru

Маркелова Елена Владимировна

Д.м.н., профессор, ФГБОУ ВО «Тихоокеанский Государственный Медицинский Университет» Минздрава России (г. Владивосток) markev2010@mail.ru

Федяшев Глеб Арнольдович

Д.м.н., профессор, ФГБОУ ВО «Тихоокеанский Государственный Медицинский Университет» Минздрава России (г. Владивосток) fediashev@mail.ru

Аннотация. В исследование включены 40 пациентов с подтвержденным диагнозом сахарный диабет 2 типа (основная группа) и 30 практически здоровых добровольцев (контрольная группа). Всем исследуемым проведена оптическая когерентная томография (ОКT) на аппарате RTVue-100 («Optovue», (ША) и микропериметрия на аппарате «MAIA» (CenterVue, Италия). При оценке результатов микропериметрии выявлено достоверное $(p=0,001)$ снижение средней светочувствительности сетчатки. Анализируя результаты ОКТ выявлена значимая $(\mathrm{p}=0,01)$ увеличение объема фокальных потерь ганглиозных клеток сетчатки (FLV) у пациентов основной группы. Выявленные изменения не зависели от наличия клинических признаков диабетической ретинопатии, что подтверждает теорию 0 том, что нейродегенеративные процессы в сетчатке возникают раньше сосудистых. Пациенты с диагнозом диабетическая полинейропатия могут иметь более высокий риск развития нейродегенеративных процессов в сетчатке.

Ключевые слова: сахарный диабет, диабетическая ретинопатия, нейродегенерация, микропериметрия, оптическая когерентная томография.

Общая численность пациентов с СД в России составляет более 4 млн., все они находятся в группе высокого риска развития серьезных осложнений, снижающих качество жизни[6]. Диабетическая ретинопатия (ДР) является одним из наиболее тяжелых осложнений СД, приводящим к необратимой потере зрения. 
Длительное время ДР рассматривалась, как сосудистое осложнение СД, но в последнее время накапливается все больше данных о том, что ДР является комплексным заболеванием при котором нейродегенеративные процессы в сетчатке играют важную роль[9-10]. Нейродегенерация при ДР в первую очередь начинается с гибели ганглиозных клеток сетчатки и уменьшения толщины сетчатки [9-10,13]. Все это усугубляет течение ДР и ухудшает прогноз заболевания. В связи с этим остается актуальным вопрос поиска методов ранней диагностики нейродегенеративных изменений сетчатки у больных СД.

В современной офтальмологической практике для изучения структурных изменений сетчатки применяется оптическая когерентная томография (ОКТ). Данный метод позволяет измерить общую толщину сетчатки и толщину ее отдельных слоев. Существуют исследования, которые выявляли уменьшение этих параметров у пациентов с СД[1,4,6,11].

Функциональное состояние сетчатки может быть оценено при помощи психофизических методов исследования, к которым относится компьютерная микропериметрия, позволяющая определить чувствительность сетчатки в центральной зоне с одномоментным сопоставлением с картиной глазного дна [7]. Преимущества метода заключаются в том, что полученные результаты не зависят от движения глазного яблока и четко соответствуют исследуемой области. В настоящее время имеются единичные исследования об информативности этого метода в диагностике нейродегенерации сетчатки [2,3].

\section{Шель исслеАования}

Изучить особенности клинико-анамнестических и структурно-функциональных показателей у больных сахарным диабетом 2 типа с нейродегенеративными изменениями сетчатки.

\section{Материал и метолы}

В исследование включены 40 пациентов, обратившихся в диагностическое отделение ООО «Приморский центр микрохирургии глаза», с подтвержденным у эндокринолога диагнозом сахарный диабет 2 типа (основная группа) и 30 практически здоровых добровольцев (контрольная группа). Основная группа была разделена на две подгруппы: в первую вошли пациенты без клинических признаков диабетической ретинопатии (20 человек), во вторую вошли пациенты с клиническими признаками непролиферативной диабетической ретинопатии (20 человек). Критериями исключения служили наличие диабетического макулярного отека, глаукомы, заболеваний макулярной области и зрительного нерва, непрозрачности оптических сред глаза. Участники ос- новной и контрольной групп были сопоставимы по полу и возрасту. Средний возраст пациентов основной группы составил 60,8 99,5 года, мужчин 42,5\%, женщин 57,5\%. Средний возраст участников контрольной группы составил 60,3 55,56 года мужчин 40\%, женщин 60\%. Все пациенты основной группы получали терапию пероральными сахароснижающими препаратами, средний стаж СД составлял 7,75 $\pm 4,06$ года, уровень гликированного гемоглобина в среднем равнялся $7,73 \pm 1,08 \%$.

Всем исследуемым проведено стандартное офтальмологическое обследование: визометрия, пневмотонометрия, биомикроскопия, офтальмоскопия в условиях медикаментозного мидриаза.

Функциональное состояние сетчатки оценивали при помощи компьютерной микропериметрии, используя аппарат «MAIA» (CenterVue, Италия). Применяли стратегию 4-2, при которой на макулярную область проецируются 37 стимулов с центром в точке фиксации (у всех пациентов она была стабильно фовеальной). Определяли среднюю световую чувствительность сетчатки, световую чувствительность в зоне фовеа, парафовеа и перифовеа, последние делились на 4 квадранта: верхний, нижний, носовой и височный. Единица измерения - децибел, дБ.

ОКТ сетчатки выполнялось с помощью аппарата RTVue-100 («Optovue», США). Карта общей толщины сетчатки, толщины ее внутренних и наружных слоев выполнялась при помощи протокола Retina Map и исследовалась в 9 зонах: фовеа (окружность диаметром 1 мм), парафовеа (окружность диаметром 3 мм), перифовеа (окружность диаметром 5 мм). Пара- и перифовеа делились на 4 квадранта: верхний, нижний, носовой и височный. Также при помощи протокола GCC определяли толщину комплекса ганглиозных клеток сетчатки (ГКС), объем фокальных (FLV) и глобальных (GLV) потерь ГKC.

Статистическая обработка результатов проводилась при помощи программы SPSS Statistics, версия 23. Показатели представлены как средняя арифметическая величина и ее стандартное отклонение (M $\mathrm{s}$ ). Сравнение количественных показателей в несвязанных выборках выполнялось с использованием критерия Манна-Уитни, ранговый коэффициент Спирмена применяли для корреляционного анализа. Различия считались достоверными при p $\leq 0,05$.

Исследование одобрено локальным этическим комитетом ФГБОУ ВО «Тихоокеанский государственный медицинский университет» Минздрава России.

\section{Результаты и обсужление}

Анализ результатов микропериметрии показал, что величина средней световой чувствительности сетчатки 
во всех группах была в пределах референтных значений. Однако у пациентов с СД 2 типа этот показатель оказал-

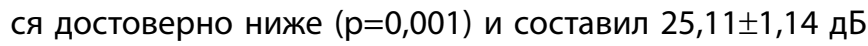
в сравнении с контрольной группой, где он был равен 27,28土1,1 дБ.

Результаты ОКТ не показали достоверно значимой разницы в общей толщине сетчатки между контрольной и основной группами. Отсутствовала достоверная разница в толщине комплекса ГКС и объеме их глобальных потерь (GLV), однако имелась значимая $(p=0,01)$ разница в объеме фокальных потерь ГKC (FLV). В основной

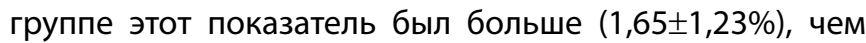
В контрольной $(0,42 \pm 0,66 \%)$. Последнее наблюдение подтверждает существующие данные о том, что процесс нейродегенерации сетчатки начинается с апоптоза ГКС.

Оценивая взаимосвязь данных микропериметрии и ОКТ, мы выявили отрицательную корреляцию между средней световой чувствительностью сетчатки и объемом фокальных потерь ГKС ( $r=-0,539, p=0,01)$. Это показывает связь между структурными и функциональными нарушениями.

Сравнивая пациентов основной группы с клиническими признаками ДР и пациентов той же группы, но без клинических признаков ДР мы не обнаружили достоверной разницы в морфофункциональном состоянии сетчатки. Данный факт подтверждает теорию о том, что нейродегенеративные изменения сетчатки при СД происходят независимо от сосудистых изменений и, возможно, имеют отдельный патогенез, что требует дальнейшего исследования.

Согласно исследованию Л.К. Мошетовой (2013г) показатель средней световой чувствительности $\leq 25,8$ дБ является пороговым и может быть использован в ка- честве диагностического критерия снижения функциональной активности сетчатки у пациентов с СД[3]. Используя этот параметр в своем исследовании, мы отметили, что в основной группе он был ниже порогового у 19 пациентов (47,5\%). Распределение по полу в этой подгруппе пациентов было следующим: 8 мужчин $(42,1 \%)$ и 11 женщин (57,9\%), полученные гендерные отличия согласуются с общим составом основной группы. Средний возраст пациентов составил 59,3土8,9 лет и статистически не отличался от возраста остальных участни-

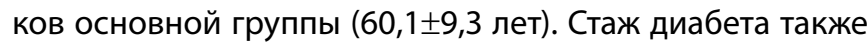
достоверно не отличался и был равен 7,2 44,3 и 6,9 $\pm 4,1$ соответственно. Также, в отличии от других авторов, мы не увидели корреляции между уровнем гликированного гемоглобина и средней светочувствительностью сетчатки[2]. Однако изучая анамнестические данные этих пациентов было выявлено, что 12 больных $(63,1 \%)$ находились на диспансерном учете у невролога с диагнозом диабетическая полинейропатия, в то время как среди остальных участников основной группы эта патология была выявлена у 3 пациентов (14,2\%). Данный факт может косвенно подтверждать теорию о том, что процесс нейродегенерации сетчатки может быть одним из вариантов периферической полинейропатии и требует отдельного исследования[12].

\section{Зак^ючение}

По результатам исследования были выявлены структурные и функциональные изменения сетчатки у пациентов с СД 2 типа, связанные с процессом нейродегенерации, которые не зависели от наличия клинических признаков ДР. Пациенты с диагнозом диабетическая полинейропатия могут иметь более высокий риск развития нейродегенеративных процессов в сетчатке. Микропериметрия и ОКТ могут быть использованы для диагностики и мониторинга данного процесса.

\section{ЛИТЕРАТУРА}

1. Кулыбышева В.С., Ронзина И. А., Гамидов А. А. Нейродегенеративные изменения сетчатки у пациентов с сахарным диабетом. // Вестник офтальмологии. 2019. № 5. 31-37.

2. Кулыбышева В. С., Ронзина И. А., Гамидов А. А. Предикторы ранних изменений при сахарном диабете. // 0фтальмология. 2020. № 17(1). С. 88-95.

3. Мошетова Л. К., Аржиматова Г. Ш., Комаров А. В. Микропериметрия при сахарном диабете 1-го типа. // Российская педиатрическая офтальмология. 2013. № 2. P. 32-37.

4. Овсепян Т. Р., Казарян А. А., Шишкин М. М. Ранние морфологические и нейрофункциональные изменения сетчатки при сахарном диабете. // Российский офтальмологический журнал. 2015. № 4. С. 83-87.

5. Шестакова М. В., Викулова 0. К., Железнякова А. В., Исаков М. А., Дедов И. И. Эпидемиология сахарного диабета в Российской Федерации: что изменилось за последнее десятилетие? // Терапевтический архив. 2019. № 10. С. 4-13.

6. Hegazy Al, Zedan RH, Macky TA, Esmat SM. Retinal ganglion cell complex changes using spectral domain optical coherence tomography in diabetic patients without retinopathy. // International Journal of Ophthalmology. 2017. № 10(3). P. 427-433.

7. Hirooka K, Misaki K, Nitta E, Ukegawa K, Sato S, Tsujikawa A. Comparison of macular integrity assessment (MAIA), MP-3, and the Humphrey field analyzer in the evaluation of the relationship between the structure and function of the macula. // PLOS ONE. 2016. № 11(3). e0151000.

8. International Diabetes Federation. Diabetes Atlas 2019. URL: https://diabetesatlas.org/ (Accessed June 20, 2019). 
9. Kadlubowska J, Malaguarnera L, Waz P, Zorena K. Neurodegeneration and neuroinflammation in diabetic retinopathy: potential approaches to delay neuronal loss. // Current Neuropharmacology. 2016. № 14(8). P. 831-839.

10. Simo R, Stitt AW, Gardner TW. Neurodegeneration in diabetic retinopathy: does it really matter? // Diabetologia. 2018. № 61(9).1902-1912.

11. Srinivasan S, Dehghani C, Pritchard N, Edwards K, Russel AW, Malik AR, Efron N. Corneal and retinal neuronal degeneration in early stages of diabetic retinopathy. // Investigative Ophthalmology Visual Science. 2017. № 58. P. 6365-6373.

12. Srinivasan S, Pritchard N, Samson G, Edwards K, Vagenas D, Russell A, Malik R, Efron N. Focal loss volume of ganglion cell complex in diabetic neuropathy. // Clinical and Experimental Optometry. 2016. № 99. P. 526-534.

13. Wolter JR. Diabetic retinopathy. // American Journal of Ophthalmology. 1961. № 51. P. 1123-1141.

( Ручкин Михаил Петрович ( michaelr-n@mail.ru ), Макаревич Екатерина Сергеевна ( katyuha-m@mail.ru ),

Маркелова Елена Владимировна ( markev2010@mail.ru ), Федяшев Глеб Арнольдович ( fediashev@mail.ru).

Журнал «Современная наука: актуальные проблемы теории и практики»

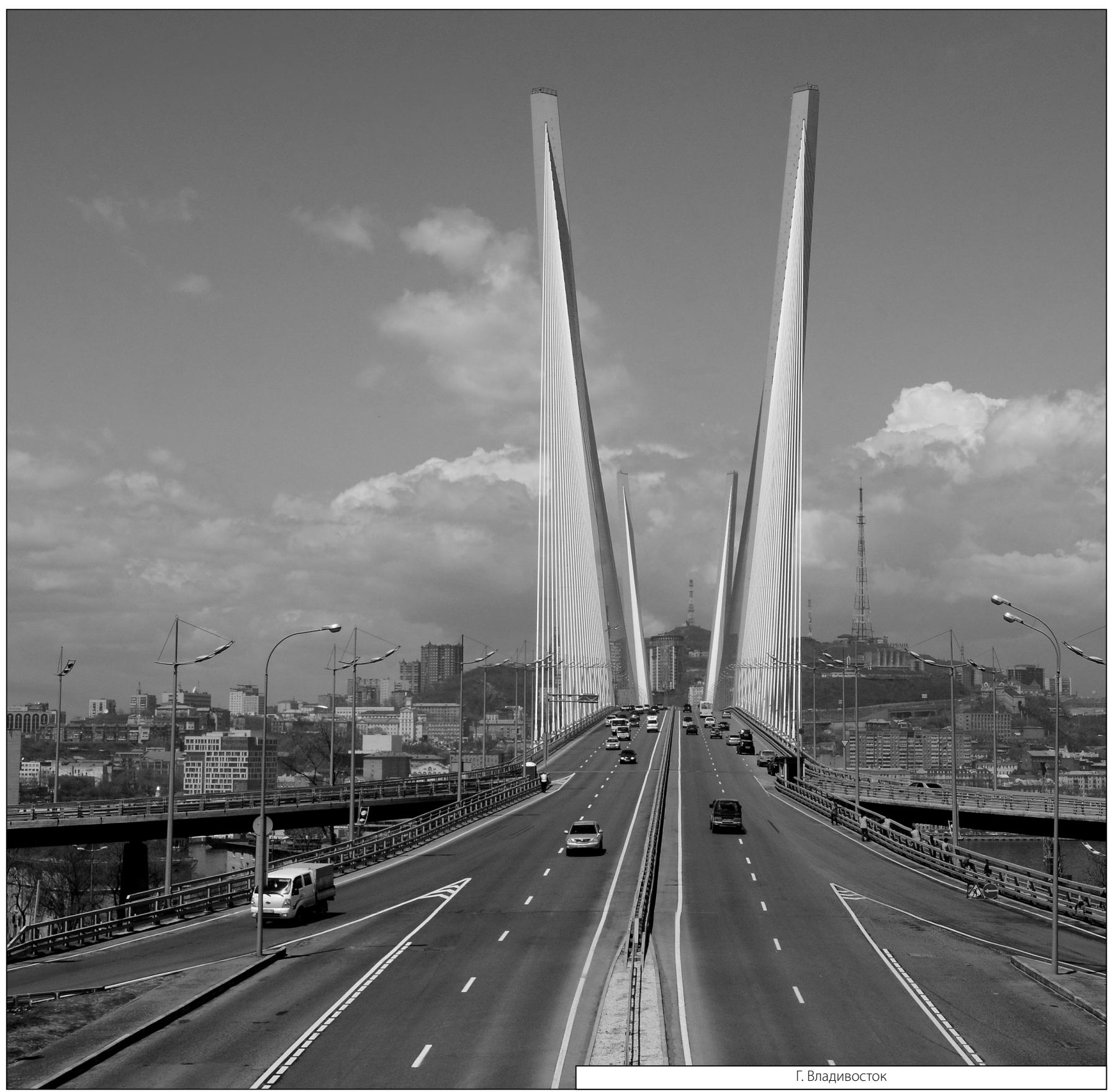

